\title{
Calcium- and proton-dependent relocation of annexin A6 in Jurkat T cells stimulated for interleukin-2 secretion
}

\author{
Paulina Podszywalow-Bartnicka, Agnieszka Strzelecka-Kiliszek, \\ Joanna Bandorowicz-Pikula and Slawomir Pikula ${ }^{凶}$ \\ Department of Biochemistry, Nencki Institute of Experimental Biology, Warszawa, Poland
}

Received: 20 February, 2007; revised: 25 April, 2007; accepted: 21 May, 2007

available on-line: 04 June, 2007

\begin{abstract}
Annexin A6 (AnxA6) is a $\mathrm{Ca}^{2+}$-dependent membrane-binding protein involved in vesicular traffic. The likely participation of AnxA6 in the response of lymphocytes to $\mathrm{Ca}^{2+}$ signals has not been investigated yet. The present study focuses on intracellular relocation of AnxA6 in human Jurkat $\mathrm{T}$ lymphoblasts upon stimulation followed by transient increase of intracellular $\left[\mathrm{Ca}^{2+}\right]$ and exocytosis of interleukin-2 (IL-2). Stimulation of the cells under different experimental conditions (by lowering $\mathrm{pH}$ and/or by rising extracellular $\left[\mathrm{Ca}^{2+}\right]$ in the presence of ionomycin) induced timedependent transients of intracellular $\left[\mathrm{Ca}^{2+}\right]$ and concomitant changes in AnxA6 intracellular localization and in IL-2 secretion, with only minor effects on cell viability and apoptosis. In resting conditions (in the presence of EGTA or with no ionophore) AnxA6 was localized uniformly in the cytosol, whereas it translocated to vesicular structures beneath the plasma membrane within 5 min following stimulation of Jurkat $\mathrm{T}$ cells and rise of intracellular $\left[\mathrm{Ca}^{2+}\right]$ at $\mathrm{pH} 7.4$. Lowering the extracellular $\mathrm{pH}$ value from 7.4 to 6.0 significantly enhanced this process. AnxA6 changed its location from the cytosol to the secretory granules and early endosomes which seem to represent membranous targets for annexin. In conclusion, AnxA6 is sensitive to variations in intracellular $\left[\mathrm{Ca}^{2+}\right]$ upon stimulation of Jurkat $\mathrm{T}$ cells, as manifested by a switch in its intracellular localization from the cytosol to vesicular structures located in close proximity to the plasma membrane, suggestive of participation of AnxA6 in calcium- and proton-dependent secretion of cytokines by lymphocytes.
\end{abstract}

Keywords: annexin A6, calcium, ionomycin, interleukin-2, vesicular traffic, Jurkat T cells

\section{INTRODUCTION}

Cytolytic T lymphocytes use two mechanisms to kill virally infected cells, tumor cells, or even other potentially autoreactive $\mathrm{T}$ cells (Esser et al., 1998). The first, the perforin/granule exocytosis, utilizes cytolytic granules containing cytokines that are delivered to the target cell to induce apoptosis and eventual lysis. This mechanism requires the release of $\mathrm{Ca}^{2+}$ from intracellular stores of the lymphocyte followed by a sustained influx of extracellular $\mathrm{Ca}^{2+}$. The second mechanism, FasL/Fas-mediated cytolysis, requires de novo synthesis of FasL by the lymphocyte and the presence of the death receptor Fas on the target cell to induce apoptosis. In this case only a sustained influx of extracellular $\mathrm{Ca}^{2+}$ is required for this mechanism to be activated. Both mechanisms point to $\mathrm{Ca}^{2+}$ as a key factor in appropriate functioning of lymphocytes. This calls for identification of calcium-binding proteins as receptors, effectors and mediators of $\mathrm{Ca}^{2+}$-dependent events, including secretion of cytokines by T lymphocytes.

Cytokines regulate cellular immune activity and are produced by a variety of cells, not only

\footnotetext{
Corresponding author: S. Pikula, Department of Biochemistry, Nencki Institute of Experimental Biology, 02-093 Warszawa, Poland; e-mail: s.pikula@nencki.gov.pl

Abbreviations: AnxA6, annexin A6; BCECF, 2',7-bis(2-carboxymethyl)-5-(and-6)-carboxyfluorescein acetoxymethyl ester; DABCO, 1,4-diazabicyclo[2.2.2] octane; IL-2, interleukin-2; DMSO, dimethylsulfoxide; PBS, phospahte-buffered saline; PI, propidium iodide; PMA, phorbol 12-myristate 13-acetate; SNARE proteins, soluble $N$-ethylmaleimide-sensitive fusion protein (NSF) attachment protein receptor proteins; TBS, Tris-buffered saline.
} 
lymphocytes, but also monocytes and macrophages. Human cytokines are most commonly assessed at the macro level by measuring their levels in serum or plasma or in supernatants of in vitro stimulated blood cells. Since the process of cell stimulation often leads to programmed cell death, in vivo stimulation, preceding in vitro stimulation, is not only of potential physiological significance but may be also of practical importance in terms of interpreting the results of in vitro stimulation of cytokine production (Walker et al., 2002). Multiparameter flow cytometry is used to examine cell-specific cytokine production after in vitro induction with phorbol 12-myristate 13-acetate (PMA) and ionomycin, in the presence of brefeldin A, monensin or other agents able to inhibit protein secretion.

In this context a challenging question is how intracellular $\mathrm{Ca}^{2+}$ transients in conjunction with signaling cascades are related to the functioning of lymphocytes, especially to their activity. Calciumbinding proteins are intracellular receptors and mediators of $\mathrm{Ca}^{2+}$ transients and special interest has been placed on their identification and characterization. Among the various families of calcium-binding proteins, annexins have gained special attention due to their ability to interact with cellular membranes in a dynamic and reversible manner as well as their potential activity as membrane fusogens, $\mathrm{Ca}^{2+}$ sensors and signal transducers in regulated exo- and endocytosis (Creutz, 1992; Donnelly \& Moss, 1997; Pons et al., 2001).

Among annexins, structurally related $\mathrm{Ca}^{2+}$-dependent membrane-binding proteins characterized by a domain structure conferring functional diversity (Edwards \& Moss, 1995; Gerke \& Moss, 2002), AnxA6 is truly unique. While other annexins contain four repetitive domains, AnxA6 has eight; each repeat domain usually contains a characteristic "type 2 " motif with the evolutionarily conserved sequence "GxGT-[38 residues]-D/E", which is responsible for binding of $\mathrm{Ca}^{2+}$ (Moss \& Morgan, 2004).

At the subcellular level, AnxA6 has been localized in the cytosol, where it is found in close association with membranous structures (Golgi apparatus, vacuoles and endoplasmic reticulum), and attached to the plasma membrane (Rambotti et al., 1993; Kaetzel et al., 1994). Therefore, AnxA6 is considered as a cytosolic protein that exists in the cell in two forms, soluble form and a $\mathrm{Ca}^{2+} /$ phospholipid/ cholesterol-dependent membrane-bound one (Gerke \& Moss, 1997; Rescher \& Gerke, 2004). In particular, changes in the intracellular distribution and concentration of cholesterol in different subcellular compartments were found to affect the reorganization of intracellular pools of $\mathrm{Ca}^{2+}$-dependent and $\mathrm{Ca}^{2+}$-independent AnxA6 (de Diego et al., 2002). Transient annexin depletion by RNA interference and the ex- pression of dominant-negative mutant proteins shed new light on the role of AnxA6 in membrane-related processes ranging from the control of membrane structure to certain membrane transport phenomena. Surprisingly, mice lacking AnxA6 showed no obvious phenotype related to a primary defect in vesicle docking and/or fusion events (Hawkins et al., 1999; Song et al., 2002). This may indicate that the lack of AnxA6 is compensated by other members of the annexin family of proteins.

AnxA6 has been implicated in a number of cellular functions, including cell growth and proliferation (Kester et al., 1997), intracellular calcium homeostasis (Fleet et al., 1999; Babiychuk \& Draeger, 2000), ion channel activity induced by GTP (Kirilenko et al., 2002) or low pH (Golczak et al., 2001a; 2001b), cytoskeleton reorganization (Rescher \& Gerke, 2004; Hayes et al., 2004), membrane dynamics (vesicular transport and membrane fusion) during exo- and endocytosis (Kubista et al., 2000; Pons et al., 2001; Gerke \& Moss, 2002), lysosomal targeting (Grewal et al., 2000) and signal transduction pathways in which a crucial role is played by Ras proteins (Donnelly \& Moss, 1998; Russo-Marie, 1999; Grewal \& Enrich, 2006).

The role of AnxA6 in secretion has not been extensively investigated, but the available data suggest that AnxA6 may block vesicle SNARE protein aggregation and fusion mediated by AnxA2 and AnxA7, perhaps by competing with them for binding sites and acting as a negative regulator of exocytosis (Donnelly \& Moss, 1997; Gerke et al., 2005). According to this idea, AnxA6 is "switched off" in lactating breast where a strong secretory stimulus is desirable, and "switched on" in cells of the immune system where a fine-tuning mechanism of secretory control is necessary (Donnelly \& Moss, 1997).

The present study focuses on a calcium- and proton-dependent sequential redistribution of AnxA6 upon ionomycin stimulation of human Jurkat T lymphoblasts to induce cytokine secretion.

\section{MATERIALS AND METHODS}

Cell culture. Human Jurkat E6.1 leukaemic T cell lymphoblasts (ECACC 88042803) were cultured in RPMI 1640 medium (Sigma) supplemented with $10 \%$ fetal bovine serum (Gibco), $100 \mathrm{U} / \mathrm{ml}$ penicillin (Sigma), $100 \mu \mathrm{g} / \mathrm{ml}$ streptomycin (Sigma) and $2 \mathrm{mM}$ L-glutamine (Sigma).

Calcium and $\mathrm{pH}$ treatment of the cells. Cells were incubated in a PD medium $(125 \mathrm{mM} \mathrm{NaCl}$, $5 \mathrm{mM} \mathrm{KCl}, 10 \mathrm{mM} \mathrm{NaHCO} 3^{\prime} 1 \mathrm{mM} \mathrm{KH_{2 }} \mathrm{PO}_{4}, 10$ $\mathrm{mM}$ glucose, $1 \mathrm{mM} \mathrm{MgCl}$, $20 \mathrm{mM}$ Hepes, $\mathrm{pH}$ 7.0) supplemented with $1 \mathrm{mM} \mathrm{CaCl}$ or $5 \mathrm{mM}$ EGTA (different $\mathrm{Ca}^{2+}$ conditions), $\mathrm{pH} 7.4$ or 6.0 (different 
$\mathrm{pH}$ conditions) for $10 \mathrm{~min}$ at room temperature. Intracellular $\left[\mathrm{Ca}^{2+}\right]$ was manipulated by incubating the cells with $5 \mu \mathrm{M}$ ionomycin (Sigma) for $10 \mathrm{~min}$ at room temp. in the presence of $1 \mathrm{mM}$ extracellular $\mathrm{Ca}^{2+}$. Ionomycin was prepared from a stock solution in DMSO; the final concentration of DMSO did not exceed $0.05 \%$ by volume.

Immunofluorescence and confocal microscopy. Cells $\left(10^{5}\right)$ were washed twice in the PD medium and incubated in the presence of $1 \mathrm{mM} \mathrm{CaCl}_{2}$ or $5 \mathrm{mM}$ EGTA, at $\mathrm{pH} 7.4$ or 6.0 , with or without $5 \mu \mathrm{M}$ ionomycin for $10 \mathrm{~min}$ at room temp. DMSO was added as a control. The cells were immediately fixed with $3 \%$ paraformaldehyde/PD for $20 \mathrm{~min}$ at room temp. The fixed cells were washed in the $\mathrm{PD}$ medium, incubated in $50 \mathrm{mM} \mathrm{NH} \mathrm{H}_{4} \mathrm{Cl} / \mathrm{PD}(10 \mathrm{~min}$, room temp.) and after washing permeabilized with $0.08 \%$ Triton $\mathrm{X}-100 / \mathrm{PD}\left(5 \mathrm{~min}, 4^{\circ} \mathrm{C}\right)$. After washing once in the PD medium, and once in Tris-buffered saline (TBS; $130 \mathrm{mM} \mathrm{NaCl}, 25 \mathrm{mM}$ Tris/HCl, pH $7.5)$, the cells were incubated in a blocking solution ( $5 \%$ fetal bovine serum/TBS) for $45 \mathrm{~min}$ at room temp. Then, the cells were exposed to primary antibodies - mouse monoclonal anti-AnxA6 (Transduction Laboratories) or rabbit polyclonal anti-Rab3A, Rab5B, Rab7 (Santa Cruz Biotechnology). After $1 \mathrm{~h}$ incubation the cells were washed six times with $0.5 \%$ fetal bovine serum/TBS/0.05\% Tween 20 (5 min each) and incubated for $1 \mathrm{~h}$ at room temp. with secondary antibodies - goat anti-mouse IgG conjugated with FITC (Sigma) or goat anti-rabbit IgG conjugated with AlexaFluor546 (Molecular Probes). All antibodies were prepared in $0.5 \%$ fetal bovine serum/TBS/0.05\% Tween 20 and applied for $1.5 \mathrm{~h}$ at room temp. In control experiments, the incubation with primary antibodies was omitted. After extensive washing (four times in $0.5 \%$ fetal bovine serum/TBS $/ 0.05 \%$ Tween 20 , two times in TBS and once in $\mathrm{H}_{2} \mathrm{O}$ ) the samples were mounted in Moviol $4-88 / 2.5 \%$ DABCO and examined under a TCS SP2 spectral confocal and multiphoton microscope (Leica). Photographs were prepared using the AdobePhotoshop software.

$\left[\mathrm{Ca}^{2+}\right]_{\text {in }}$ measurements. Intracellular (cytosolic) $\left[\mathrm{Ca}^{2+}\right]$ was measured with the fluorescent probe Fura-2/AM (Molecular Probes) as described in (Grynkiewicz et al., 1985). Five million cells were loaded with the probe by incubating in the culture medium supplemented with $1 \mu \mathrm{M}$ Fura-2/AM for $15 \mathrm{~min}$ at $37^{\circ} \mathrm{C}$. After washing by centrifugation the cells were suspended in the PD medium supplemented with $1 \mathrm{mM} \mathrm{CaCl}_{2}$ in different $\mathrm{pH}$ conditions (7.4 or 6.0$)$ and $\left[\mathrm{Ca}^{2+}\right]_{\text {in }}$ was monitored fluorimetrically. The fluorescence was continuously measured at $30^{\circ} \mathrm{C}$ in a Shimadzu RF5000 fluorimeter set in the ratio mode using $340 \mathrm{~nm} / 380 \mathrm{~nm}$ as excitation wavelengths and $510 \mathrm{~nm}$ as the emission wavelength.
Time resolution of the measurements was one second. $\left[\mathrm{Ca}^{2+}\right]_{\text {in }}$ was calibrated in each run by the addition of $10 \mu \mathrm{M}$ ionomycin followed by the addition of 100 mM EGTA.

Intracellular $\mathbf{p H}$ measurements. Intracellular $\mathrm{pH}$ was measured with the fluorescent probe 2',7bis(2-carboxymethyl)-5-(and-6)-carboxyfluorescein acetoxymethyl ester (BCECF/AM, Molecular Probes), according to Rink and co-workers (Rink et al., 1982). Five million cells were loaded with the probe by incubating in the culture medium supplemented with $1 \mu \mathrm{M}$ BCECF/AM for $15 \mathrm{~min}$ at $37^{\circ} \mathrm{C}$. Thereafter, the cells were washed and suspended in the PD medium supplemented with $1 \mathrm{mM} \mathrm{CaCl}$ at different $\mathrm{pH}$ conditions (7.4 or 6.0) as described for $\left[\mathrm{Ca}^{2+}\right]_{\text {in }}$ measurements. The fluorescence was measured at $30^{\circ} \mathrm{C}$ in a Shimadzu RF5000 fluorimeter set in the ratio mode using $500 \mathrm{~nm}$ (for unprotonated BCECF) and 450 (for protonated BCECF) as the excitation wavelengths and $530 \mathrm{~nm}$ as the emission wavelength. The assay system was calibrated by titration with $\mathrm{NaOH}$ or $\mathrm{HCl}$ in the presence of $0.003 \%$ digitonin.

Cytokine secretion assay. For intracellular cytokine analysis, $3 \times 10^{6}$ Jurkat $\mathrm{T}$ cells in $1 \mathrm{ml}$ of serum-free medium were used (Sullivan et al., 2000; Batliwalla et al., 2000; Walker et al., 2002). Cells were incubated in the presence of $1 \mathrm{mM} \mathrm{CaCl}$ or $5 \mathrm{mM}$ EGTA, at pH 7.4 or 6.0 , with $0.05 \%$ DMSO or $5 \mu \mathrm{M}$ ionomycin for $4 \mathrm{~h}$ at $37^{\circ} \mathrm{C}$ in the presence of $10 \mu \mathrm{g} /$ $\mathrm{ml}$ brefeldin A (Sigma). After being washed in PBS/ brefeldin $\mathrm{A}$, the cells were stained for $30 \mathrm{~min}$ at $4^{\circ} \mathrm{C}$ in the dark with R-PE-conjugated mouse anti-human CD4 monoclonal antibody prepared in staining buffer $(3 \%$ fetal bovine serum $/ 0.09 \%$ sodium azide/PBS $\mathrm{pH}$ 7.4) according to the manufacturer's protocol (Beckton Dickinson PharMingen Int.). After washing 2 times in staining buffer the cells were fixed with $1 \%$ paraformaldehyde/PBS (20 $\mathrm{min}$, room temp.), washed in PBS and permeabilized with $0.1 \%$ saponin $/ 0.09 \%$ sodium azide/PBS (10 $\mathrm{min}$, room temp.). After washing in PBS the cells were stained for $1 \mathrm{~h}$ at room temp. in the dark with FITC-conjugated rat anti-human IL-2 monoclonal antibody prepared in staining buffer. After washing 2 times in PBS the flow cytometry analysis of intracellular IL-2 was performed.

Cell viability and apoptosis analysis. For identification of live cells by propidium iodide (PI) staining, $10^{6}$ cells were washed twice in the PD medium, suspended in $2 \mathrm{ml}$ of PI solution $(50 \mu \mathrm{g} / \mathrm{ml} \mathrm{PI}$ in the PD medium) and then used directly for flow cytometry analysis. For apoptosis analysis, $3 \times 10^{6}$ cells were incubated in an appropriate buffer, and then in RPMI medium supplemented with $10 \%$ fetal bovine serum for $24 \mathrm{~h}$. Afterwards the cells were centrifuged at $500 \times g$ for $3 \mathrm{~min}$ and the pellet was suspended in $1 \mathrm{ml}$ PBS. The cell suspension was 
added into $2.5 \mathrm{ml}$ of absolute $\mathrm{EtOH}$ (final concentration approx. $70 \%$ ) and incubated over night at $-20^{\circ} \mathrm{C}$. Then the cells were centrifuged and suspended in $500 \mu \mathrm{l}$ of PI solution ( $50 \mu \mathrm{g} / \mathrm{ml}$ PI, $0.1 \mathrm{mg} / \mathrm{ml}$ RNase, $0.05 \%$ Triton $\mathrm{X}-100$ in PBS) for $40 \mathrm{~min}$ at $37^{\circ} \mathrm{C}$. After that, $3 \mathrm{ml}$ of PBS was added, cells were centrifuged, the supernatant was discarded while the pellet was resuspended in $1 \mathrm{ml}$ PBS for flow cytometry analysis.

Flow cytometry. A FACScan flow cytometer (Becton-Dickinson) equipped with an argon laser emitting at $488 \mathrm{~nm}$ was used. FITC fluorescence was monitored by FL1 (570 V logarithmic) emission channel whereas PI as well as R-PE fluorescence were monitored by FL2 (470 V linear) emission channel. The number of cells (\%) was counted using the CellQuest software (Becton-Dickinson) from $10^{4}$ cells per each experimental set.

\section{RESULTS}

\section{$\mathrm{Ca}^{2+}$ - and $\mathrm{H}^{+}$-dependent relocation of AnxA6}

Previous studies demonstrated $\mathrm{Ca}^{2+}$ - and $\mathrm{H}^{+}$dependent binding of annexins, such as AnxA7 and AnxA6, to biological and artificial lipid membranes (Bandorowicz et al., 1992; Sen at al., 1997; Clemen et al., 2001; Golczak et al., 2001a). In this report we followed the cellular distribution of AnxA6 protein using immunohistochemistry and fluorescence methods. For our experiments we chose Jurkat $\mathrm{T}$ lymphoblasts that are characterized by a high level of AnxA6 expression (Dubois et al., 1995). To observe the effects of varying $\left[\mathrm{Ca}^{2+}\right]_{\text {in }}$ and $\left[\mathrm{H}^{+}\right]_{\text {in }}$ on the subcellular distribution of AnxA6, $\left[\mathrm{Ca}^{2+}\right]$ and $\left[\mathrm{H}^{+}\right]$ in Jurkat $\mathrm{T}$ cells were manipulated by incubating the cells for up to $10 \mathrm{~min}$ with or without ionomycin (added in DMSO) and in the presence of $5 \mathrm{mM}$ EGTA or $1 \mathrm{mM} \mathrm{CaCl}$ in the extracellular medium and either at $\mathrm{pH} 7.4$ or $\mathrm{pH}$ 6.0. In control cells (in the presence of $5 \mathrm{mM}$ EGTA at $\mathrm{pH}$ 7.4) the main pool of AnxA6 was homogenously distributed in the cytoplasm, independently of whether the cells were taken directly from the culture or after $10 \mathrm{~min}$ of incubation in the PD medium (Fig. 1A; see the Materials and Methods section). Lowering the extracellular $\mathrm{pH}$ to 6.0 in the presence of $5 \mathrm{mM}$ EGTA resulted in staining of the plasma membrane (indicated by white arrows in Fig. 1B) and of the perinuclear region of the cell (indicated by yellow arrows in Fig. 1B). In the presence of $1 \mathrm{mM} \mathrm{CaCl}$, without the ionophore at $\mathrm{pH} 7.4$ also two types of AnxA6 cell localization were observed - beneath the plasma membrane (indicated by white arrows in Fig. 1C) and in the cytosol (indicated by yellow arrows in Fig. 1C). Lowering the extracellular $\mathrm{pH}$ to 6.0 in the presence of $1 \mathrm{mM} \mathrm{CaCl}$ resulted in a punctate localization of AnxA6 on the plasma membrane (indicated by white arrows in Fig. 1D) and on the membranes of vesicular structures resembling endosomes or exosomes (indicated by yellow arrows in Fig. 1D).

Ionomycin treatment of lymphocytes in the presence of $1 \mathrm{mM} \mathrm{CaCl}$ led to a relocation of the whole cell AnxA6 pool to the membrane of small vesicles localized throughout the cell as well as to the plasma membrane (Figs. 2 and 3). These changes were less pronounced at $\mathrm{pH} 7.4$ although the $\left[\mathrm{Ca}^{2+}\right]_{\text {in }}$ increased up to $6 \mu \mathrm{M}$ within a time span of $10 \mathrm{~min}$ upon incubation with ionomycin in the presence of $1 \mathrm{mM} \mathrm{CaCl}$ in the external medium (Fig. 2, lower panel). The scattered character of the $\mathrm{Ca}^{2+}$ fluxes at $\mathrm{pH} 7.4$ in the presence of ionophore is probably related to the magnitude of $\mathrm{Ca}^{2+}$ oscillations accompanying the process. It is worth mentioning that cells incubated in the presence of $1 \mathrm{mM}$ extracellular $\mathrm{Ca}^{2+}$ but without the ionophore are characterized by low $\left[\mathrm{Ca}^{2+}\right]_{\mathrm{in}}$, within the range of 30 to $50 \mathrm{nM}$, similar to values already reported in the literature. In the presence of ionomycin at $\mathrm{pH} 7.4$ no significant differences in AnxA6 localization were observed for the first $1 \mathrm{~min}$ after ionomycin addition; most of the protein persisted in the cytoplasm, however, after 5-10 min, plasma membrane staining (indicated by white arrows in Fig. 2, upper panel) as well as the vesicle membrane-bound form (indicated by yellow arrows in Fig. 2, upper panel) of AnxA6 were observed.

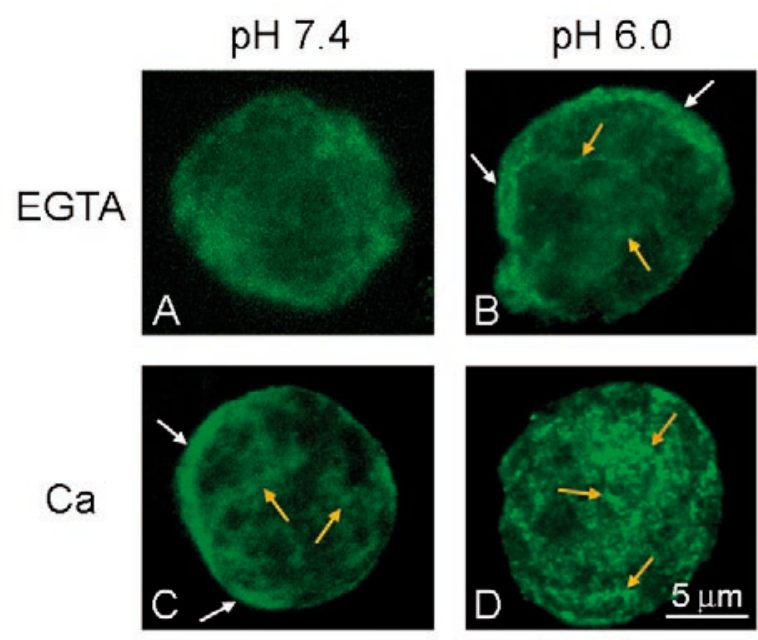

Figure 1. Localization of AnxA6 in non-stimulated Jurkat T cells.

The cells were incubated in the PD medium at $\mathrm{pH} 7.4(\mathrm{~A}$, C) or $\mathrm{pH} 6.0(\mathrm{~B}, \mathrm{D})$, in the presence of either $5 \mathrm{mM}$ EGTA $(\mathrm{A}, \mathrm{B})$ or $1 \mathrm{mM} \mathrm{CaCl}_{2}(\mathrm{C}, \mathrm{D})$. After fixation and permeabilization of the cells, localization of AnxA6 was detected by mouse anti-AnxA6 followed by goat anti-mouse-FITC staining using confocal laser scan microscopy (white arrows - plasma membrane, yellow arrows - perinuclear region or vesicles). 

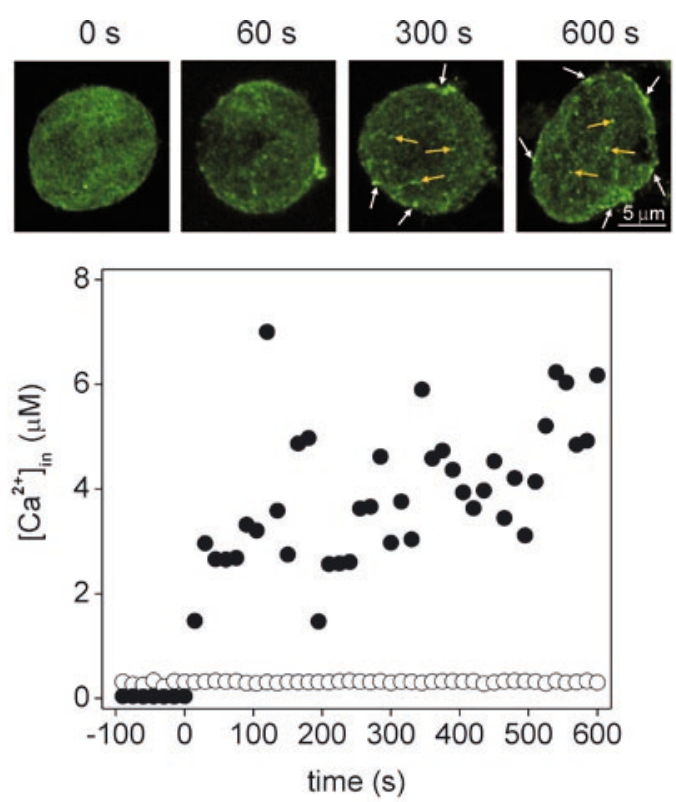

Figure 2. $\mathrm{Ca}^{2+}$-dependent translocation of AnxA6 in Jurkat $\mathrm{T}$ cells at $\mathrm{pH}$ 7.4.

$\left[\mathrm{Ca}^{2+}\right]_{\text {in }}$ was manipulated by incubating the cells in the $\mathrm{PD}$ medium at $\mathrm{pH} 7.4$ in the presence of $1 \mathrm{mM} \mathrm{CaCl}_{2}$. At the time indicated on the figure (upper panel) $5 \mu \mathrm{M}$ ionomycin (or $0.05 \%$ DMSO) was added and the cells were withdrawn after $0,60,300$ or $600 \mathrm{~s}$ for immediate fixation. After fixation and permeabilization, the subcellular location of AnxA6 was detected by mouse anti-AnxA6 followed by goat anti-mouse-FITC staining and confocal laser scan microscopy (white arrows - plasma membrane, yellow arrows - vesicles). Changes of $\left[\mathrm{Ca}^{2+}\right]_{\text {in }}$ in Jurkat $\mathrm{T}$ cells were monitored fluorimetrically (lower panel), as described in the Materials and Methods section. DMSO $(0.05 \%$, open symbols) or $5 \mu \mathrm{M}$ ionomycin (solid symbols) were added at time 0 . One typical determination out of three is shown.

To slow down the calcium uptake by Jurkat $\mathrm{T}$ cells in the presence of ionomycin and $1 \mathrm{mM}$ external $\mathrm{CaCl}_{2}$ we lowered the $\mathrm{pH}$ of the external medium to 6.0. Under these conditions, between 1 to $5 \mathrm{~min}$ after addition of the ionophore AnxA6 accumulated in association with membranes of vesicular structures in the perinuclear region of the cell (indicated by yellow arrows in Fig. 3, upper panel). After $10 \mathrm{~min}$ AnxA6 finally relocated to the plasma membrane (indicated by white arrows in Fig. 3, upper panel). These changes were preceded at $\mathrm{pH} 6.0$ by changes in $\left[\mathrm{Ca}^{2+}\right]_{\text {in }}$ reaching the maximum of $544.08 \pm 114.44$ $\mathrm{nM}$ within $30 \mathrm{~s}$ after addition of the ionophore and then transiently decreasing within $10 \mathrm{~min}$ to a new resting $\left[\mathrm{Ca}^{2+}\right]_{\text {in }}$ of $182.89 \pm 13.03 \mathrm{nM}$ (Fig. 3, lower panel). Lowering the extracellular $\mathrm{pH}$ from 7.4 to 6.0 in the absence of ionophore did not affect $\left[\mathrm{Ca}^{2+}\right]_{\text {in' }}$ while the intracellular $\mathrm{pH}$ dropped from $6.92 \pm 0.01$ to $6.38 \pm 0.04$. It is worth to note that addition of DMSO to the cells did not influence $\left[\mathrm{Ca}^{2+}\right]_{\text {in }}$ at any
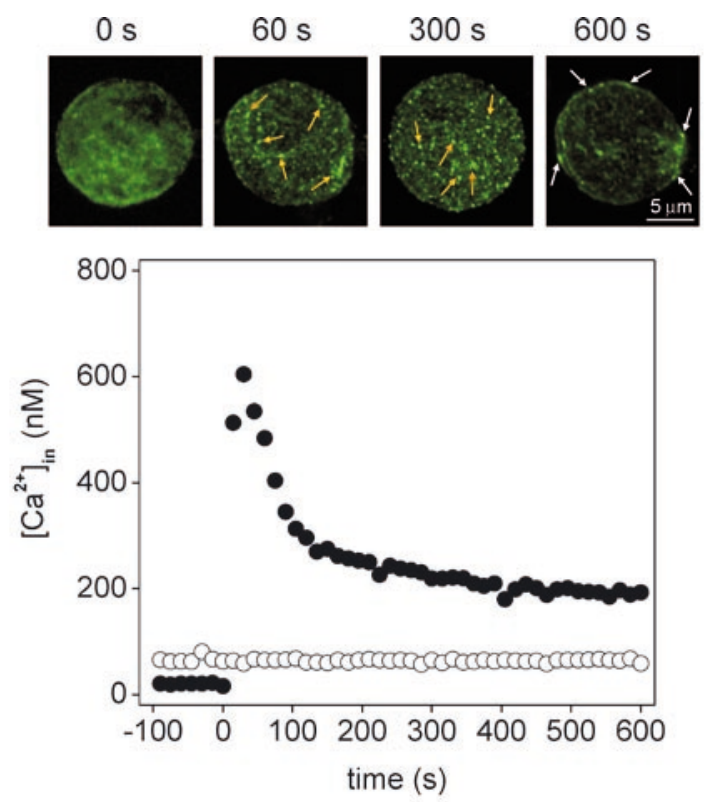

Figure 3. $\mathrm{Ca}^{2+}$-dependent translocation of AnxA6 in Jurkat $\mathrm{T}$ cells at $\mathrm{pH} 6.0$.

$\left[\mathrm{Ca}^{2+}\right]_{\text {in }}$ was manipulated by incubating the cells in the PD medium at $\mathrm{pH}$ 6.0, in the presence of extracellular $\mathrm{CaCl}_{2}$ $(1 \mathrm{mM})$. At the time indicated on the figure (upper panel) $5 \mu \mathrm{M}$ ionomycin (or $0.05 \%$ DMSO) was added and the cells were fixed and permeabilized. The subcellular location of AnxA6 was detected by mouse anti-AnxA6 followed by goat anti-mouse-FITC staining and confocal laser scan microscopy (white arrows - plasma membrane, yellow arrows - vesicles in perinuclear region). Changes of $\left[\mathrm{Ca}^{2+}\right]_{\text {in }}$ in Jurkat $\mathrm{T}$ cells were monitored fluorimetrically (lower panel), as described in the Materials and Methods section. DMSO $(0.05 \%$, open symbols) or $5 \mu \mathrm{M}$ ionomycin (solid symbols) were added at time 0. One typical determination out of three is shown.

$\mathrm{pH}$ values, and the spectral properties of Fura-2/AM were not affected at low $\mathrm{pH}$.

Our immunohistochemistry and fluorescence results presented above suggest that AnxA6 relocates to the membranous structures of the cell upon stimulation. To identify the type of membranes to which AnxA6 preferentially binds we examined the localization of AnxA6 in comparison with markers of various vesicular structures in control and stimulated Jurkat $\mathrm{T}$ cells (Fig. 4). In cells treated with EGTA AnxA6 staining did not change with $\mathrm{pH}$ and the protein did not co-localize with any of the markers examined (Fig. 4A-F). Changes in intracellular $\left[\mathrm{Ca}^{2+}\right]$ induced by incubation of the cells in the presence of $1 \mathrm{mM} \mathrm{CaCl}$ in the extracellular medium at $\mathrm{pH} 7.4$ induced AnxA6 translocation to intracellular membranes located near the plasma membrane, identified by co-localization with Rab3A as secretory granules that may participate in the first phase of regulated secretion (indicated 

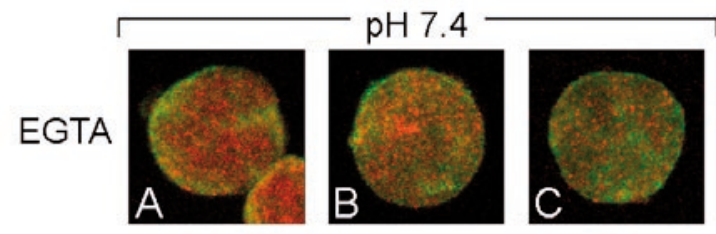

$\mathrm{Ca}$
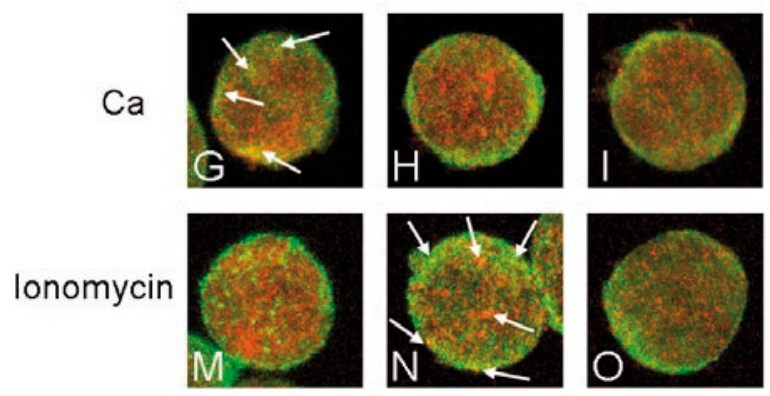

Rab3A

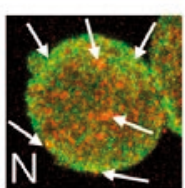

Rab5B

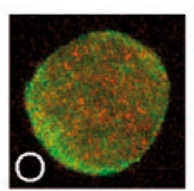

Rab7
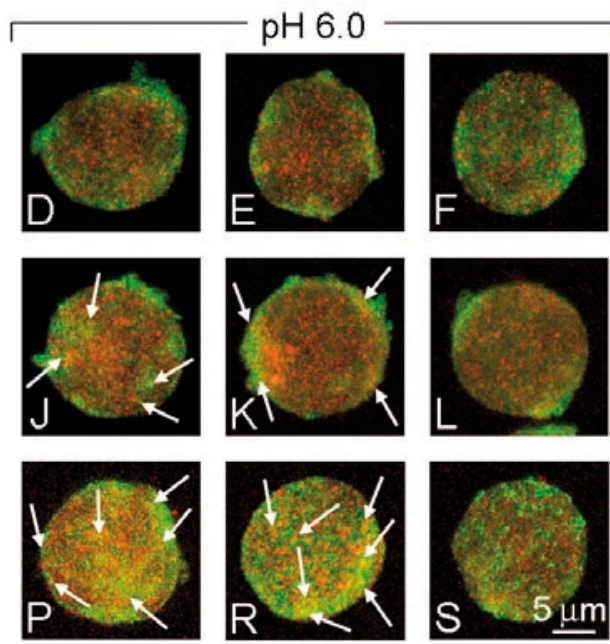

Rab5B

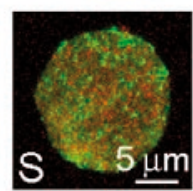

Rab7

Figure 4. $\mathrm{Ca}^{2+}$ - and $\mathrm{H}^{+}$-dependent translocation of AnxA6 to membranous compartments in Jurkat $\mathrm{T}$ cells.

The cells were incubated in the PD medium at $\mathrm{pH} 7.4$ (A, B, C, G, H, I, M, N, O) or pH 6.0 (D, E, F, J, K, L, P, R, S), in the presence of either $5 \mathrm{mM}$ EGTA $(\mathrm{A}, \mathrm{B}, \mathrm{C}, \mathrm{D}, \mathrm{E}, \mathrm{F}), 1 \mathrm{mM} \mathrm{CaCl}_{2}(\mathrm{G}, \mathrm{H}, \mathrm{I}, \mathrm{J}, \mathrm{K}, \mathrm{L})$ or $1 \mathrm{mM} \mathrm{CaCl}_{2}$ and $5 \mu \mathrm{M}$ ionomycin (M, N, O, P, R, S). After fixation and permeabilization of the cells, localization of AnxA6 together with Rab3A (A, D, G, J, M, P), Rab5B (B, E, H, K, N, R) or Rab7 (C, F, I, L, O, S) was detected by mouse anti-AnxA6 antibody and with rabbit anti-Rab3A, Rab5B or Rab7 antibodies, followed by goat anti-mouse-FITC together with goat anti-rabbit-AlexaFluor546 staining, using confocal laser scan microscopy (arrows - protein co-localization indicated by yellow color of merged photographs).

by arrows in Fig. 4G). Mild acidification of the medium enhanced the staining of AnxA6 in exosomal membranes in the cytosol (indicated by arrows in Fig. 4J) and induced translocation of this protein beneath the plasma membrane to early endosomes identified by Rab5B staining (indicated by arrows in Fig. 4K). Upon the rise of intracellular $\left[\mathrm{Ca}^{2+}\right]$ due to the presence of ionophore, AnxA6 was found attached to the vesicular structures identified as early endosomes by distribution of their marker protein, Rab5B (indicated by arrows in Fig. 4N). Extracellular $\mathrm{pH} 6.0$ significantly enhanced this process. Thus, two populations of AnxA6 can be distinguished: one associated with early endosomes (indicated by arrows in Fig. 4R) and the other with membranous structures identified by co-localization with Rab3A as secretory granules (indicated by arrows in Fig. 4P) participating, most probably, in the second phase of regulated secretion. There was no co-staining of AnxA6 with Rab7, a marker of late endosomes, under our experimental conditions (Fig. 4F, L, S).

\section{$\mathrm{Ca}^{2+}$ - and $\mathrm{H}^{+}$-dependent secretion of interleukin-2}

Measurement of cytokine production is a valuable adjunct to standard immunological assays in defining several pathological processes (Sullivan et al., 2000), therefore we performed detection of intracellular cytokines using a technique in which cells are permeabilized and antibodies are used to detect cytokines by flow cytometry (Batliwalla et al., 2000; Walker et al., 2002). We examined the effect of changes in $\left[\mathrm{Ca}^{2+}\right]_{\text {in }}$ induced by incubation of Jurkat $\mathrm{T}$ cells with or without ionomycin and in the presence of $5 \mathrm{mM}$ EGTA or $1 \mathrm{mM} \mathrm{CaCl}_{2}$ in the extracellular medium on IL-2 production by these cells (Fig. 5). The experiments were performed at $\mathrm{pH} 7.4$ (filled bars) or $\mathrm{pH} 6.0$ (open bars) in the presence of brefeldin A, an agent able to inhibit protein secretion, in order to determine the secretory granules containing IL-2 inside the cells. At $\mathrm{pH} 7.4$ in control conditions (no further additions, Fig. 5A and $\mathrm{B}, \mathrm{a}$ ) or when the cells were treated with EGTA (Fig. 5A and $\mathrm{B}, \mathrm{b}$ ) or $\mathrm{CaCl}_{2}$ (Fig. 5A and $\mathrm{B}, \mathrm{C}$ ) or DMSO (Fig. 5A and B, d) but without the ionophore, the majority of Jurkat $\mathrm{T}$ cells are able to express CD4 (not shown), while IL-2 is produced by a small number of cells $(6.9 \pm 3.7 \%$ for $10 \mathrm{~min}$ stimulation, Fig. $5 \mathrm{~A}$, a-d, and $4.8 \pm 0.1 \%$ for $4 \mathrm{~h}$ stimulation, Fig. 5B, a-d). At pH 6.0 (Fig. 5 , open bars) the production of IL-2 was slightly inhibited in control cells as compared to $\mathrm{pH} 7.4$ (Fig. 5, filled bars). Ionomycin treatment in the presence of $1 \mathrm{mM} \mathrm{CaCl}$ led to an increase in the number of cells producing IL-2 to $9.7 \pm 3.8 \%$ of the cell population after $10 \mathrm{~min}$ at $\mathrm{pH} 7.4$ (Fig. 5A, e, filled bars) but longer stimulation up to $4 \mathrm{~h}$ was necessary to reach a statistically significant difference in the number of cells producing IL-2 (an increase to $42.2 \pm 10.4 \%$, Fig. $5 \mathrm{~B}$, e, filled bars). The changes presented above were less pronounced at 


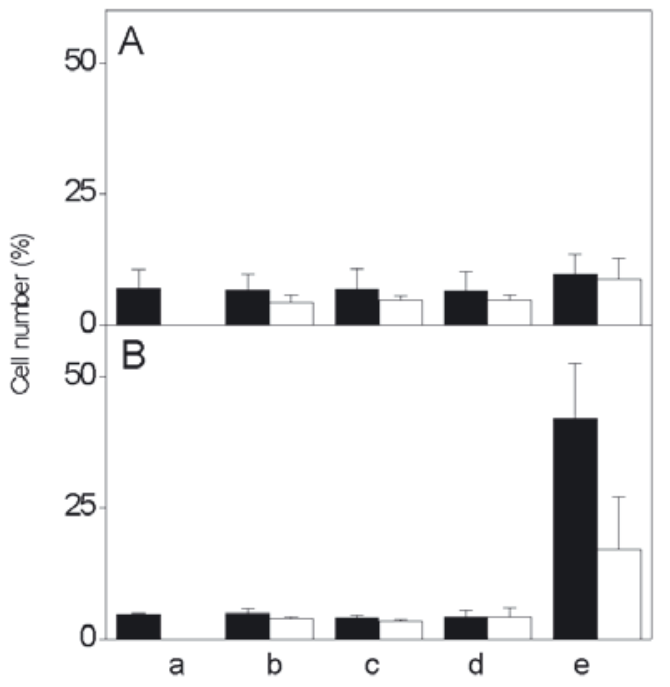

Figure 5. $\mathrm{Ca}^{2+-}$ and $\mathrm{H}^{+}$-dependent cytokine secretion by Jurkat $\mathrm{T}$ cells.

Intracellular $\left[\mathrm{Ca}^{2+}\right]$ and $\left[\mathrm{H}^{+}\right]$were manipulated by incubating the cells for $10 \mathrm{~min}(\mathrm{~A})$ or $4 \mathrm{~h}(\mathrm{~B})$ in the PD medium at $\mathrm{pH} 7.4$ (filled bars) or 6.0 (open bars) with no further additions (a) or in the presence of $5 \mathrm{mM}$ EGTA (b), $1 \mathrm{mM} \mathrm{CaCl}$ (c), $0.05 \%$ DMSO (d) or $5 \mu \mathrm{M}$ ionomycin and $\mathrm{CaCl}_{2}$ (e) as indicated. Cells were stained with R-PE-anti-CD4, fixed, permeabilized, and then stained with FITC-anti-IL-2 (see the Materials and Methods section). Brefeldin A $(10 \mu \mathrm{g} / \mathrm{ml})$ was present in the media throughout the experiment. The number of cells with intracellular IL-2 (FITC) fluorescence was measured by flow cytometry. Results are expressed as means \pm S.E. of three experiments.

pH 6.0 when the number of cells producing IL-2 did not exceed $20 \%$ even after $4 \mathrm{~h}$ of stimulation (Fig. 5A and B, e, open bars). Cell activation with ionomycin caused a statistically non significant decrease in CD4 expression in the cells, as reported earlier in the literature (Andersson \& Coleclough, 1993), regardless of the external $\mathrm{pH}$.
Viability of Jurkat $T$ cells under experimental conditions

Taking into consideration that conditions used during our experiments could affect cell viability, we analyzed it by PI staining. No significant differences in cell viability could be detected between the experimental variants (Table 1). Staining of fixed cells with PI revealed that $24 \mathrm{~h}$ after treatment of cells with $1 \mathrm{mM} \mathrm{CaCl}$ and ionomycin for $10 \mathrm{~min}$ at $\mathrm{pH} 7.4$, up to $32 \%$ of the cells underwent apoptosis. Treatment of the cells with ionomycin at $\mathrm{pH} 6.0 \mathrm{did}$ not result in an extensive apoptosis $(<7 \%$, Table 2$)$.

\section{DISCUSSION}

In the present study we addressed the problem of a potential role of AnxA6 in calcium-dependent secretion of cytokines by $\mathrm{T}$ lymphocytes upon stimulation leading to changes in intracellular ion homeostasis. Lymphocytes have been proven to be a good model to investigate exocytosis. Two forms of exocytosis can be distinguished - constitutive, in which vesicle formation is followed by an immediate fusion, and regulated, in which vesicles may wait in the cytoplasm for a signal before fusion is initiated (Donnelly \& Moss, 1997). In the latter case, the rise in calcium concentration may be restricted to localized regions immediately beneath the plasma membrane and this may prevent vesicles in the cell interior from docking and fusing with the membrane. The activation of $\mathrm{T}$ lymphocytes through the TCR/CD3 complex results in an enhanced induction of the autocrine growth factor IL-2, governing expansion of antigenic T cells (Nell et al., 2002). Inducible expression of IL-2 is tightly regulated by multiple transcription factors that bind at distinct sites on the IL-2 promoter (Jhun et al., 2005). Ionomycin and PMA are commonly used in in vitro experiments for

Table 1. Viability of Jurkat $\mathrm{T}$ cells in different experimental conditions.

The cells were incubated in the PD medium essentially as described in the legends to Figs. 1-4. Live cells were identified by PI staining and flow cytometry analysis, as described in the Materials and Methods section. The results of one typical experiment are presented.

\begin{tabular}{lccccc}
\hline \multicolumn{5}{c}{ Live cells (\%) } \\
\hline $\mathrm{pH}$ & Time (s) & $5 \mathrm{mM} \mathrm{EGTA}$ & $1 \mathrm{mM} \mathrm{CaCl}_{2}$ & $0.05 \%$ DMSO & $5 \mu \mathrm{M}$ inomycin \\
\hline 7.4 & 60 & 97.82 & 98.55 & 98.44 & 97.22 \\
7.4 & 300 & 94.82 & 98.03 & 97.87 & 97.31 \\
7.4 & 600 & 93.05 & 97.01 & 96.42 & 95.65 \\
6.0 & 60 & 98.23 & 97.93 & 98.79 & 98.14 \\
6.0 & 300 & 94.43 & 97.20 & 97.94 & 96.33 \\
6.0 & 600 & 93.83 & 96.55 & 97.25 & 95.07 \\
\hline
\end{tabular}


Table 2. Apoptosis in Jurkat $\mathrm{T}$ cells.

The cells were incubated in the PD medium for $10 \mathrm{~min}$ essentially as described in the legends to Figs. 1-4 and then were grown for additional $24 \mathrm{~h}$. Apoptotic cells were identified by fixation, PI staining and flow cytometry analysis, as described in the Materials and Methods section. The results from two experiments are presented.

\begin{tabular}{lcccc}
\hline \multicolumn{5}{c}{ Apoptotic cells (\%) } \\
\hline $\mathrm{pH}$ & $5 \mathrm{mM}$ EGTA & $1 \mathrm{mM} \mathrm{CaCl}_{2}$ & $0.05 \%$ DMSO & $5 \mu$ M ionomycin \\
\hline 7.4 & $2.70-5.10$ & $2.71-5.47$ & $3.04-5.10$ & $13.83-32.37$ \\
6.0 & $2.29-5.93$ & $3.37-7.03$ & $3.28-5.88$ & $4.06-6.82$ \\
\hline
\end{tabular}

stimulation of Jurkat $\mathrm{T}$ cells. It is well established that in the presence of those agents stimulated lymphocytes secrete cytokines (Marti et al., 2001; Pardo et al., 2003). Our studies revealed that an increase in intracellular $\left[\mathrm{Ca}^{2+}\right]$ caused a major fraction of Jurkat $\mathrm{T}$ cells to synthesize CD4, but a smaller fraction produced IL-2, in agreement with observations made by other investigators (Batliwalla et al., 2000). Therefore, we have proven that a several hour-long incubation of the cells in the presence of $1 \mathrm{mM} \mathrm{CaCl}{ }_{2}$ and ionophore at $\mathrm{pH} 7.4$ is a useful experimental procedure to stimulate a significant number of Jurkat $\mathrm{T}$ cells to secrete cytokine. We are aware that in order to obtain a direct proof of the involvement of AnxA6 in cytokine secretion a quantitative determination of IL-2 using ELISA in cell cultures of control and activated T cells, with AnxA6 overexpression or silencing, would be valuable.

When we analyzed the subcellular distribution of AnxA6 in non-stimulated Jurkat T cells, we observed that the main pool of AnxA6 is localized in the cytoplasm (under these conditions, $\left[\mathrm{Ca}^{2+}\right]$ is strongly reduced in the presence of EGTA). Higher concentrations of $\mathrm{Ca}^{2+}$ and $\mathrm{H}^{+}$in the culture medium induced punctate staining throughout the cell, probably indicative of binding of AnxA6 to vesicular structures. An effective $\mathrm{Ca}^{2+}$ influx across the plasma membrane of Jurkat $\mathrm{T}$ cells was achieved using ionomycin (external $\left[\mathrm{Ca}^{2+}\right]=1 \mathrm{mM}, \mathrm{pH}$ 6.0). In a time frame of $10 \mathrm{~min}$, we first observed a shift of AnxA6 from the cytosol to the secreting plasma membrane (Rab3A-positive) and later from the perinuclear region to the vesicular membranes identified by us as Rab5B-positive early endosomes, indicating a $\mathrm{Ca}^{2+}-$ and $\mathrm{H}^{+}$-dependent transfer of AnxA6 molecules to different membrane systems in the cell. Our results are in agreement with the most recent knowledge about AnxA6 as a very dynamic protein that seems to shuttle between the cytosol, cell surface and exoas well as endocytic compartments (Gerke et al., 2005). Elevation of $\left[\mathrm{Ca}^{2+}\right]_{\text {in }}$ induced the translocation of cytosolic and membrane-bound AnxA6 to ordered (lipid rafts/caveolae) and disordered regions of the plasma membrane playing a modulatory role in spatiotemporal Ras/MAPK and Ras/p120 GAP signaling
(Grewal et al., 2004; Grewal \& Enrich, 2006). A similar behavior, e.g. $\mathrm{Ca}^{2+}$ - and $\mathrm{H}^{+}$-dependent intracellular relocation from the cytosol to cellular membranes was reported for AnxA7 and occurred within $17 \mathrm{~s}$ (Clemen et al., 2001). In the cited study, an increase in $\left[\mathrm{Ca}^{2+}\right]_{\text {in }}$ was achieved by incubating the cells with $10 \mu \mathrm{M}$ ionomycin in the presence of $1 \mathrm{mM}$ extracellular $\mathrm{Ca}^{2+}$ at $\mathrm{pH}$ 8.2. In another set of experiments, the binding of secretory granules, their aggregation and fusion was activated in a concentration-dependent manner by AnxA7 and arachidonic acid, but only at low calcium concentrations $(10 \mu \mathrm{M})$ and at pH 6.0 (Sen et al., 1997). In cells treated with a calcium ionophore (A23187) and PMA AnxA7 binding to the membrane fraction increased by $120 \%$, with a concomitant decrease of the cytosolic pool of the protein by $40 \%$, in comparison to non-stimulated control cells (Chander et al., 2003). All these reports suggest that upon a stimulus of certain strength annexins are able to change their intracellular localization from the cytosol to cellular membranes where they can perform specific functions likely related to the membrane dynamic processes accompanying vesicular transport.

In this report, ionomycin stimulation of Jurkat $\mathrm{T}$ cells and the concomitant influx of $\mathrm{Ca}^{2+}$ from the extracellular millieu mimicking physiological processes were achieved at $\mathrm{pH}$ 6.0. It could be related to the sensitivity of junctional ion channels. It has been reported that acidification of the external millieu to $\mathrm{pH} 6.3$ depressed the conductance of junctional channels by directly or indirectly affecting channel proteins (Abudara et al., 2001). The problematic part of the use of ionomycin is that it may induce apoptosis-like events in the cells, such as membrane blebbing, mitochondrial depolarization, externalization of phosphatidylserine and nuclear permeability changes observed within 15 min of treatment (Casas et al., 2006). This could be at least partially reversed by overexpression of phospholipase $\mathrm{A}_{2}$ or pretreating the cells with arachidonic acid (Casas et al., 2006).

We suggest that AnxA6 with its well established $\mathrm{Ca}^{2+}$ - and $\mathrm{H}^{+}$-dependent membrane binding property and high level of expression in Jurkat $\mathrm{T}$ 
cells could be considered as an important molecule playing a role in secretory granule-plasma membrane fusion and/or secretion of cytokines by $\mathrm{T}$ lymphocytes. Our co-localization studies showed that changes in intracellular $\left[\mathrm{Ca}^{2+}\right]$ induced by incubation of the cells in the presence of $1 \mathrm{mM}$ external $\mathrm{CaCl}_{2}$ at $\mathrm{pH} 7.4$ induced AnxA6 translocation to Rab3Apositive secretory granules likely participating in the first phase of regulated secretion during which docked granules are primed to be readily releasable and triggered for fusion with the plasma membrane. Under such conditions the number of cells producing IL-2 found in our flow cytometry analysis was significantly higher comparing to control cells. Performing the experiments at $\mathrm{pH} 6.0$ permitted us to show that AnxA6 participates also in the second phase of regulated secretion, during which a reserve pool of store granules is supplied for docking or directly triggered for plasma membrane fusion. The number of cells producing IL-2 was not so impressive but this may be explained by the inhibitory action of AnxA6 on vesicle aggregation and fusion mediated by AnxA2 and AnxA7, as reported by other investigators (Zaks \& Creutz, 1990). A role of annexins, among them AnxA6, in secretion has already been postulated and attributed to controlling intracellular calcium mobilization, to regulation of vesicular trafficking, and to inhibition of phospholipase $\mathrm{A}_{2}$ activity and blood coagulation (Creutz, 1992; Donnelly \& Moss, 1997). In addition, a link between calcium signaling, low $\mathrm{pH}$ compartments in exocytosis and AnxA6 was recently established on the basis of an analysis of mutant mice with reduced levels of AnxA6 (Song et al., 2002). Moreover, AnxA6 was found to participate in a concentration-dependent release of $\mathrm{Ca}^{2+}$ from chromaffin granules (Jones et al., 1994). Considering the predominant localization of AnxA6 as attached to the apical region of the plasma membrane, the observations listed above may suggest that this protein could participate in the secretory events by mediating the localized release of $\mathrm{Ca}^{2+}$ at contact sites between chromaffin granules and the plasma membrane. If vesicle aggregation depends on annexin-mediated contact formation between neighboring membranes, it is conceivable that AnxA6 may disrupt this interaction by competing with AnxA2 for critical binding sites. It has been proposed (Donnelly \& Moss, 1997) that AnxA2 heterotetramer may form a bridge between the faces of two adjacent vesicles while AnxA6, with its unique spatial configuration, could disrupt this bridge by competing for AnxA2 binding sites on the lipid membrane. Some investigators propose a SNAREbased membrane-fusion model in which addition of some annexins and $\mathrm{Ca}^{2+}$ accelerate the fusion process by improving the kinetics of the initial membrane-contact formation, whereas addition of other annexins may inhibit the fusion process by shielding membrane surfaces (Gerke et al., 2005). Our strategy to use ionophore as a non-physiological stimulus of lymphocytes and mild extracellular acidification was key to resolving the problem whether only the calcium- and low pH-dependent pool of AnxA6 is the candidate to be the secretory inhibitor. The phenomenon that the expression of AnxA6 in circulating T and B lymphocytes, as compared to immature cells of both lineages, correlates with a secretory phenotype confirmed that for tightly controlled processes such as secretion, proteins like AnxA6 that act as negative regulators provide the cell with a more sophisticated system of control than positive mediators alone (Donnelly \& Moss, 1997).

\section{CONCLUSIONS}

In conclusion, we suggest that AnxA6 belongs to a family of vesicular traffic mediators or vesicular traffic markers that are regulated by intracellular calcium transients. In the present study, we have demonstrated that AnxA6 expressed in Jurkat $\mathrm{T}$ lymphoblasts responds to intracellular $\mathrm{Ca}^{2+}$ and $\mathrm{H}^{+}$transients by sequential redistribution from the cytoplasm to the vesicular structures located beneath the plasma membrane that represent either storage organelles or exosomes actually on the way to the plasma membrane to secrete cytokines upon a $\mathrm{Ca}^{2+}\left(\mathrm{and} / \mathrm{or} \mathrm{H}^{+}\right)$stimulus. Further experiments, like treatment of cells by other stimulators (PMA/ionomycin, calcium ionophore A23187, calcineurin) and agonists (adenosine analog AICAR, GSK-53, cyclosporine A) of IL2 production, are necessary to better understand the functional role of AnxA6 isoforms in vesicular traffic in lymphocytes, especially to establish the involvement of either isoform in intracellular transport of cytokines, fusion of vesicles with the plasma membrane, and secretion.

\section{Acknowledgements}

This work was supported by grant N301 049 31/1592 from the Ministry of Science and Higher Education.

\section{REFERENCES}

Abudara V, Jiang RG, Eyzaguirre C (2001) Acidic regulation of junction channel between glomus cells in the rat carotic body. Possible role of $\left[\mathrm{Ca}^{2+}\right]_{\mathrm{i}}$. Brain Res 916: 50-60.

Andersson S, Coleclough C (1993) Regulation of CD4+ and CD8+ expression on mouse T-cells. J Immunol 151: 5123-5134. 
Babiychuk EB, Drager A (2000) Annexins in cell membrane dynamics. $\mathrm{Ca}^{2+}$-regulated association of lipid microdomains. J Cell Biol 150: 1113-1124.

Bandorowicz J, Pikula S, Sobota A (1992) Annexins IV (p32) and VI (p68) interact with erythrocyte membrane in a calcium-dependent manner. Biochim Biophys Acta 1105: 201-206.

Batliwalla FM, Rufer N, Lansdorp PM, Gregersen PK (2000) Oligoclonal expansion in the CD8+CD28- T cells largely explain the shorter telomeres detected in this subset: analysis by flow FISH. Human Immunol 61: 951-958.

Casas J, Gijon MA, Vigo AG, Crespo MS, Balsinde J, Balboa MA (2006) Overexpression of cytosolic group IVA phospholipase A2 protects cells from $\mathrm{Ca}^{2+}$-dependent death. J Biol Chem 281: 6106-6116.

Chander A, Sen N, Naidu DG, Spitzer AR (2003) Calcium ionophore and phorbol ester increase membrane binding of annexin A7 in alveolar type II cells. Cell Calcium 33: 11-17.

Clemen CS, Herr C, Lie AA, Noegel AA, Schröder R (2001) Annexin VII: an astrogial protein exhibiting a $\mathrm{Ca}^{2+}$-dependent subcellular distribution. NeuroReport 12: 11391144.

Creutz CE (1992) The annexins and exocytosis. Science 258: 924-951.

de Diego I, Schwartz F, Siegfried H, Dauterstedt P, Heeren J, Beisiegel U, Enrich C, Grewal T (2002) Cholesterol modulates the membrane binding and intracellular distribution of annexin 6. J Biol Chem 277: 32187-32194.

Donnelly SR, Moss SE (1997) Annexins in the secretory pathway. Cell Mol Life Sci 53: 533-538.

Donnelly SR, Moss SE (1998) Functional analysis of the human annexin I and VI gene promoters. Biochem J 332: 681-687.

Dubois T, Soula M, Moss SE, Russo-Marie F, Rothhut B (1995) Potential interaction between annexin VI and a $56-\mathrm{kDa}$ protein kinase in $\mathrm{T}$ cells. Biochem Biophys Res Commun 212: 270-278.

Edwards HC, Moss SE (1995) Functional and genetic analysis of annexin VI. Mol Cell Biochem 149/150: 293-299.

Esser MT, Haverstick DM, Fuller CL, Gullo CA, Braciale VL (1998) $\mathrm{Ca}^{2+}$ signaling modulates cytolytic T lymphocyte effector functions. J Exp Med 187: 1057-1067.

Fleet A, Ashworth R, Kubista H, Edwards H, Bolsover S, Mobbs P, Moss SE (1999) Inhibition of EGF-dependent calcium influx by annexin VI is splice form-specific. Biochem Biophys Res Commun 260: 540-546.

Gerke V, Moss SE (1997) Annexins and membrane dynamics. Biochim Biophys Acta 1357: 129-154.

Gerke V, Moss SE (2002) Annexins: from structure to function. Physiol Rev 82: 331-371.

Gerke V, Creutz CE, Moss SE (2005) Annexins: linking $\mathrm{Ca}^{2+}$ signalling to membrane dynamics. Nat Rev Mol Cell Biol 6: 449-461.

Golczak M, Kicinska A, Bandorowicz-Pikula J, Buchet R, Szewczyk A, Pikula S (2001a) Acidic pH-induced folding of annexin VI is a prerequisite for its insertion into lipid bilayers and formation of ion channels by the protein molecule. FASEB J 15: 1083-1085.

Golczak M, Kirilenko A, Bandorowicz-Pikula J, Pikula S (2001b) Conformational states of annexin VI in solution induced by acidic $\mathrm{pH}$. FEBS Lett 496: 49-54.

Grewal T, Enrich C (2006) Molecular mechanisms involved in Ras inactivation: the annexin A6-p120 GAP complex. BioEssays 28: 1211-1220.

Grewal T, Heeren J, Mewawala D, Schnitgerhans T, Wendt D, Salomon G, Enrich C, Beisiegel U, Jackle S (2000) Annexin VI stimulates endocytosis and is involved in the trafficking of low density lipoprotein to the prelysosomal compartment. J Biol Chem 275: 33806-33813.

Grynkiewicz G, Poenie M, Tsien RY (1985) A new generation of $\mathrm{Ca}^{2+}$ indicators with greatly improved fluorescence properties. J Biol Chem 260: 3440-3450.

Hawkins TE, Roes D, Monkhouse J, Moss SE (1999) Immunological development and cardiovascular function are normal in annexin VI null mutant mice. Mol Cell Biol 19: $8028-8032$.

Hayes MJ, Rescher U, Gerke V, Moss SE (2004) Annexinactin interactions. Traffic 5: 571-576.

Jhun BS, Oh YT, Lee JY, Kong Y, Yoon K-S, Kim SS, Baik HH, Ha J, Kang I (2005) AICAR suppresses IL-2 expression through inhibition of GSK-3 phosphorylation and NF-AT activation in Jurkat T cells. Biochem Biophys Res Commun 332: 339-346.

Jones PG, Fitzpatrick S, Waismann DM (1994) Chromaffin granules release calcium on contact with annexin VI: implications for exocytosis. Biochemistry 33: 8180-8187.

Kaetzel MA, Pula G, Campos B, Uhrin P, Horseman N, Dedman JR (1994) Annexin VI isoforms are differentially expressed in mammalian tissues. Biochim Biophys Acta 1223: 368-374.

Kester HA, van der Leede BM, van der Saag PT, van der Burg B (1997) Novel progesterone target genes identified by an improved differential display technique suggest that progestin-induced growth inhibition of breast cancer cells coincides with enhancement of differentiation. J Biol Chem 272: 16637-16643.

Kirilenko A, Golczak M, Pikula S, Buchet R, BandorowiczPikula J (2002) GTP-induced membrane binding and ion channel activity of annexin VI: is annexin VI a GTP biosensor? Biophys J 82: 2737-2745.

Kubista H, Sacre S, Moss SE (2000) Annexins and membrane fusion. Subcell Biochim 34: 73-131.

Marti F, Krause A, Post NH, Lyddane C, Dupont B, Sadelain M, King PD (2001) Negative-feedback regulation of CD28 costimulation by a novel mitogen-activated protein kinase phosphatase, MKP6. J Immunol 166: 197-206.

Moss SE, Morgan RO (2004) The annexins. Genome Biology 5: $219-226$

Nell AE (2002) T-cell activation through the antygen receptor. Part 2: signaling components, signaling pathways, and signal integration at the T-cell antygen receptor synapse. J Allergy Clin Immunol 109: 758-770.

Pardo J, Buferne M, Martinez-Lorenzo MJ, Naval J, Schmitt-Verhulst AM, Boyer C, Anel A (2003) Differential implication of protein kinase $\mathrm{C}$ isoforms in cytotoxic $\mathrm{T}$ lymphocyte degranulation and TCR-induced Fas ligand expression. Int Immunol 15: 1441-1450.

Pons M, Grewal T, Rius E, Schnitgerhans T, Jackle S, Enrich $C$ (2001) Evidence for the involvement of annexin 6 in the trafficking between the andocytic compartment and lysosomes. Exp Cell Res 269: 13-22.

Rambotti MG, Spreca A, Donato R (1993) Immunocytochemical localization of annexins V and VI in human placentae of different gestational ages. Cell Mol Biol Res 39: 579-588.

Rescher U, Gerke V (2004) Annexins - unique membrane binding proteins with diverse functions. J Cell Sci 117: 2631-2639.

Rink TJ, Tsien RY, Pozzan T (1982) Cytoplasmic pH and free $\mathrm{Mg}^{2+}$ in lymphocytes. J Cell Biol 95: 189-196.

Russo-Marie F (1999) Annexin V and phospholipid metabolism. Clin Chem Lab Med_37: 287-291.

Sen N, Spitzer AR, Chander A (1997) Calcium-dependence of synexin binding may determine aggregation and fusion of lamellar bodies. Biochem J 322: 103-109. 
Song G, Harding SE, Duchen MR, Tunwell R, O'Gara P, Hawkins TE, Moss SE (2002) Altered mechanical properties and intracellular calcium signaling in cardiomyocytes from annexin 6 null-mutant mice. FASEB J 16: 622-624.

Sullivan KE, Cutilli J, Piliero LM, Ghavimi-Alagha D, Starr SE, Campbell DE, Douglas SD (2000) Measurement of cytokine secretion, intracellular protein expression, and mRNA in resting and stimulated peripheral blood mononuclear cells. Clin Diag Lab Immunol 7: 920-924.
Walker D, Jason J, Wallance K, Slaughter J, Whatley V, Han A, Nwanyanwu OC, Kazembe PN, Dobbie H, Archibald L, Jarvis WR (2002) Spontaneous cytokine production and its effect on induced production. Clin Diag Lab Immunol 9: 1049-1056.

Zaks WJ, Creutz CE (1990) Annexin-chromaffin granule membrane interactions: a comparative study of synexin, p37 and p67. Biochim Biophys Acta 1020: 149-160. 